\title{
Implementasi Sistem Informasi Akuntansi Menggunakan Aplikasi Accurate untuk Perusahaan Garmen XYZ
}

\author{
Joshua Ronaldo Citra ${ }^{1}$, Rinabi Tanamal ${ }^{2}$ \\ 1,2 Information Technology, Universitas Ciputra, Citraland CBD Boulevard, Surabaya

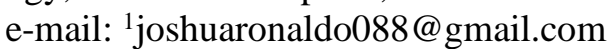 \\ e-mail: ${ }^{2}$ r.tanamal@ ciputra.ac.id
}

\begin{abstract}
Nowadays in Indonesia, the company needs toward information system is an absolute thing. Information System has become one of the components in a company. There are many positive advantages obtained in using information system. Information system has many types such as Accounting Information System (AIS) supporting the accounting in company. XYZ is an company engaged in garment in Surabaya. As a company, it has business processes related to accounting. To support the accounting process in XYZ company, it needs an accounting application. Accurate is an application providing AIS service created by CPSSoft. Accurate is chosen because the use is simple and it provides modules which support business process of companies. The problem faced by XYZ company in this research was how to arrange Accounting Information System in XYZ company using Accurate application and to overcome the problems. Thus, there would be some activities. First was interview and observation of business process in XYZ. The second was data transfer from the previous application to Accurate. The third was installment and training the Accurate to the staffs and the owner of XYZ company. Accurate could ease business process and enhance staff performance and the owner of company.
\end{abstract}

Keyword: Accurate, Accounting, Information System

\section{Pendahuluan}

Di Indonesia, peranan Teknologi Informasi (TI) menjadi sangat penting bagi suatu perusahaan, seiring dengan perkembangan teknologi yang semakin pesat dan banyaknya jumlah perusahaan yang menggunakan TI. Maraknya penggunaan TI di perusahaan-perusahaan di Indonesia disebabkan oleh berbagai hal, salah satunya adalah karena TI dapat membuat proses bisnis di suatu perusahaan menjadi lebih efisien dan akurat. TI juga dapat menyediakan Sistem Informasi (SI) untuk kebutuhan perusahaan. Sistem informasi adalah kumpulan dari beberapa prosedur yang dijalankan untuk mencapai suatu tujuan, yaitu memberikan informasi kepada para pengambil keputusan serta mengendalikan jalannya suatu organisasi atau perusahaan. (Wijaya, 2015). Sistem informasi juga dapat didefinisikan sebagai kombinasi antara software, hardware, orang-orang, jaringan komunikasi dan sumber daya data yang memiliki tujuan untuk mengumpulkan, mengubah, dan menyebarkan informasi dalam sebuah organisasi (Anggraeni \& Irviani, 2017).

Sistem Informasi sendiri menyediakan berbagai macam jenis, salah satunya ialah Sistem Informasi Akuntansi (SIA). SIA adalah Sistem
Informasi Akuntansi (SIA) adalah jaringan dari seluruh prosedur, formulir-formulir, catatancatatan, dan alat-alat yang digunakan untuk mengolah data keuangan menjadi suatu bentuk laporan yang akan digunakan oleh pihak-pihak terkait dalam mengendalikan kegiatan suatu perusahaan dan dapat digunakan sebagai alat pengambilan keputusan para pengambil keputusan (stakeholder). SIA juga dapat diartikan sebagai sekelompok struktur dalam sebuah entitas yang mengelola sumber daya fisik dan sumber daya lain untuk mengubah data ekonomi menjadi informasi akuntansi, yang digunakan dan disebarkan untuk memenuhi kebutuhan informasi berbagai pihak (Mahatmyo, 2014). SIA merupakan sub sistem yang merupakan satu kesatuan sistem business process yang saling terkait satu sama lain. Tujuan utama dari SIA adalah untuk menciptakan kontrol internal suatu perusahaan agar tercipta kondisi manajemen yang sehat. Selain itu, SIA memiliki beberapa tujuan lainnya, yaitu:

Mengumpulkan dan menyimpan data yang berkaitan dengan aktivitas keuangan perusahaan. Memproses data-data yang dibutuhkan menjadi informasi yang dapat digunakan untuk membantu proses pengambilan keputusan. (Marina, 2017) 
SIA memegang peranan cukup vital dalam suatu perusahaan, karena dengan adanya SIA, maka suatu perusahaan dapat mengetahui serta mengawasi segala proses bisnis yang berkaitan dengan proses akuntansi yang sedang berjalan di suatu perusahaan. Selain itu, SIA dapat memberikan bantuan berupa analisa akuntansi yang sangat dibutuhkan untuk pengambilan keputusan yang berkaitan dengan proses bisnis yang berjalan di perusahaan tersebut.

Karena perannya yang cukup vital bagi suatu perusahaan, perangkat-perangkat lunak (software) yang menyediakan SIA haruslah memiliki tingkat efisiensi dan keakuratan yang tinggi. Di Indonesia sendiri cukup banyak software yang menyediakan modul SIA, salah satunya ialah Accurate. Accurate merupakan software akuntansi yang dibuat sejak tahun 1999 oleh CPSSoft.

Perusahaan XYZ adalah suatu perusahaan yang bergerak di bidang garmen. Dalam kegiatan bisnisnya, perusahaan XYZ telah melaksanakan proses tersebut dengan menggunakan software lain. Fitur yang ada pada software tersebut juga sudah memenuhi kebutuhan akuntansi dari perusahaan XYZ sendiri, seperti laporan buku besar, laporan laba rugi, laporan stok barang, proses pembelian bahan baku ke supplier dan penjualan ke pelanggan, dan lain sebagainya. Namun, dalam prosesnya, software yang dipakai oleh perusahaan XYZ tidak berjalan secara optimal sebagaimana mestinya. Oleh karena itu, perlu diadakan beberapa perubahan untuk membantu perusahaan XYZ dalam memberikan solusi untuk pengganti software akuntansinya.

\section{Metodologi Penelitian}

Untuk mendapatkan informasi-informasi dari perusahaan XYZ yang dibutuhkan oleh penulis dalam proses implementasi ini, maka penulis menggunakan dua cara, yaitu wawancara dan observasi. Wawancara digunakan untuk mendapatkan informasi-informasi yang terkait dengan proses bisnis perusahaan XYZ berdasarkan dari sudut pandang pengetahuan para staf, sedangkan observasi dilakukan untuk melihat dan menganalisa secara langsung proses bisnis yang terjadi di perusahaan XYZ.

Wawancara adalah suatu proses komunikasi antara dua orang atau lebih, di mana satu pihak menjadi pewawancara dan yang lain menjadi narasumber. Wawancara bertujuan untuk mendapatkan informasi yang dibuthkan dari narasumber yang memiliki kompetensi. Wawancara dilakukan oleh pewawancara dengan cara memberikan pertanyaan kepada narasumber (Hareka \& Tanamal, 2018). Wawancara memiliki berbagai macam, yaitu wawancara terstruktur, wawancara semi terstruktur, dan wawancara tidak terstruktur (Edi, 2016).

Observasi adalah bagian dari pengumpulan data yang dilakukan secara langsung dari lapangan (Raco, 2010). Observasi memiliki tujuan, yaitu agar dapat mengungkapkan sasaran yang ingin dicapai dalam proses ini hingga selesai (Ni'matuzaroh \& Prasetyaningrum, 2018).

Setelah wawancara dan observasi, maka dilakukan pembuatan standard operating procedure (SOP). SOP adalah panduan yang digunakan untuk memastikan kegiatan operasional organisasi atau perusahaan berjalan dengan lancer, dan memiliki tujuan yaitu memastikan suatu organisasi berjalan secara konsisten, efektif, efisien, sistematis, dan terkelola dengan baik (Soemohadiwidjojo, 2014).

Kemudian, proses dilanjutkan dengan melakukan proses implementasi. Implementasi adalah proses transformasi suatu rencana yang sudah dibuat sedemikian rupa menjadi kegiatan praktik (Dachi, 2017).

\section{Diskusi}

\subsection{Analisa Kebutuhan Sistem}

Pada suatu proses implementasi, tentunya diperlukan sebuah analisis sistem yang terkait pada suatu perusahaan yang menjadi klien implementasi, dalam kasus ini ialah perusahaan XYZ. Analisis kebutuhan sistem ini bertujuan untuk mengetahui proses bisnis apa saja yang terjadi di perusahaan $\mathrm{XYZ}$, baik yang berhubungan secara langsung atau tidak langsung dengan penggunaan software dan kebutuhan yang dibutuhkan oleh perusahaan XYZ terkait software Accurate. Secara garis besar, proses bisnis yang terjadi di perusahaan XYZ meliputi proses penjualan, proses produksi dan proses keuangan/finance.

Perusahaan XYZ memiliki beberapa prosedur operasional untuk menunjang proses bisnis perusahaan XYZ. Namun, dari sekian banyak prosedur operasional tersebut, tidak ada satupun prosedur yang dibuat dalam bentuk diagram alir/flowchart. Hal tersebut berpotensi menimbulkan kerancuan atau kebingungan akan satu prosedur operasional yang ada di perusahaan $\mathrm{XYZ}$, karena adanya kemungkinan interpretasi setiap orang berbeda-beda dalam menafsirkan prosedur yang ada.

Untuk kebutuhan akan Sistem Informasi Akuntansi, perusahaan XYZ sudah menggunakan 
aplikasi yang dioperasikan di setiap komputer yang ada di perusahaan XYZ, namun aplikasi tersebut belum memenuhi ekspektasi dari perusahaan dalam hal penyajian laporan, sehingga perlu adanya pergantian aplikasi untuk dapat memenuhi kebutuhan sesuai dengan yang diperlukan.

Implementasi ini dilakukan untuk memenuhi dua kebutuhan utama yang sudah ditulis sebelumnya, yaitu pembuatan flowchart untuk menggambarkan Standar Operasional Prosedur (SOP) yang ada di perusahaan XYZ, serta penerapan aplikasi Accurate untuk menggantikan aplikasi sebelumnya, agar Sistem Informasi Akuntansi di perusahaan XYZ dapat berjalan secara optimal, dan pengambilan keputusan yang diambil oleh pemilik perusahaan dapat menghasilkan keputusan yang baik berkat laporanlaporan yang disediakan oleh Accurate.

\subsection{Sistem Organisasi}

Dalam suatu perusahaan, tentunya terdapat struktur organisasi yang dibuat agar proses bisnis yang sedang berlangsung dapat berjalan dengan optimal, serta pembagian tugasnya pun dapat dibagi secara jelas. Berikut struktur organisasi yang terdapat pada perusahaan XYZ:

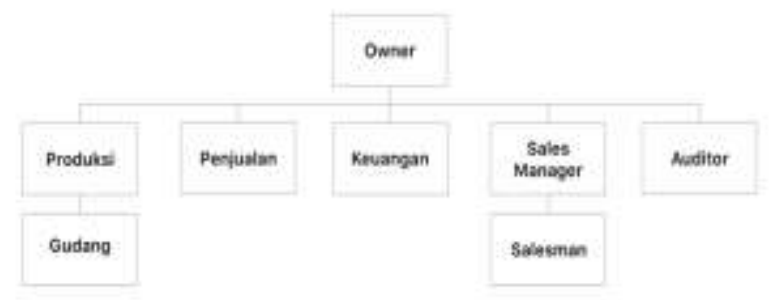

Fig. 1 Struktur organisasi perusahaan XYZ

\subsection{Penjabaran Tugas}

Seperti yang sudah dijelaskan pada poin 3.2, perusahaan XYZ memiliki beberapa divisi yang dibawahi secara langsung oleh sang pemilik/owner. Dibawah ini, akan dijabarkan tugas-tugas tiap divisi yang terdapat pada perusahaan XYZ:

\section{Owner}

Membuat data customer baru, kedua yaitu memberikan hak akses kepada user pada beberapa proses di Accurate, ketiga ialah melakukan pembayaran pembelian dan penerimaan penjualan, dan terakhir ialah melakukan retur pembelian.

2. Keuangan

Mencatat pengeluaran perusahaan (pembayaran beban, pembelian ke supplier, penggajian karyawan, dan lain-lain). Lalu mencatat pemasukkan perusahaan (penjualan customer, pencatatan kas kecil, dan lain-lain). Ketiga ialah menyelesaikan proses job costing yang telah dibuat oleh bagian produksi, membuat Daftar Penagihan Piutang (DPP), serta melakukan proses stock opname bersama bagian gudang.

\section{Produksi}

Mencatat bahan baku dari supplier yang masuk ke perusahaan XYZ. Lalu mencatat perpindahan barang dari gudang ke gudang, mencatat job costing ketika barang jadi dari penjahit telah sampai di perusahaan XYZ (Menambah qty barang jadi di Accurate), kemudian memasukkan data bahan baku yang baru ke dalam Accurate dan melakukan proses stok opname bersama bagian gudang.

\section{Penjualan}

Membuat sales order, delivery order, sales invoice, dan sales return. Lalu mengecek histori / rekam jejak customer sebelum membuat Sales Order dan lain-lain, dan membuat data barang jadi yang baru ke dalam Accurate.

5. Auditor

Memastikan SOP yang telah dibuat dapat berjalan secara optimal serta melakukan pengawasan terhadap proses-proses bisnis yang terjadi di perusahaan XYZ.

\section{Sales Manager}

Memberikan tugas dan mengawasi salesman-salesman yang bekerja serta ikut dalam proses negosiasi ke pelanggan.

7. Gudang

Melakukan stock opname dalam rentang waktu yang sudah ditentukan, melakukan pengecekan kuantitas barang yang akan dipesan oleh pelanggan, kemudian melakukan pengiriman barang ke ekspedisi, dan melakukan pencatatan stok kuantitas barang secara manual (tanpa menggunakan Accurate).

\section{Salesman}

Melakukan penawaran produk perusahaan XYZ, baik kepada pelanggan lama maupun calon pelanggan dan melakukan penagihan kepada pelanggan.

\subsection{Proses Bisnis}

Untuk proses bisnis yang dimiliki oleh perusahaan XYZ, dibagi menjadi dua, yaitu prosedur penjualan dan prosedur pembelian. Prosedur penjualan menyangkut hubungan antara perusahaan XYZ dengan pelanggan, sedangkan prosedur pembelian menyangkut hubungan antara perusahaan XYZ dan pemasok bahan baku.

Proses pembelian yang dilakukan oleh perusahaan XYZ ialah, perusahaan XYZ membeli bahan baku ke supplier atau pemasok kain. Setelah 
perusahaan XYZ melakukan pembayaran, pemasok mengirimkan kain beserta surat jalan kepada perusahaan XYZ. Staf gudang menerima kain, dan staf produksi menerima surat jalan dari pemasok. Staf produksi melakukan penambahan data kain ke dalam kartu stok, dan memasukkan data ke dalam Accurate dengan menggunakan form 'Penerimaaan Barang'.

Proses penjualan yang terjadi di perusahaan XYZ ialah, setelah menerima pesanan dari pelanggan, salesman akan menyampaikan pesanan kepada staf penjualan. Staf penjualan memproses pesanan dengan membuat sales order di Accurate. Sales order diberikan kepada staf gudang untuk dilakukan pengecekkan ketersediaan barang. Setelah barang dicek dan stoknya ada, maka staf penjualan akan membuat delivery order di Accurate sebagai surat jalan yang nantinya diberikan kepada bagian ekpedisi. Kemudian staf penjualan membuat sales invoice sebagai bukti penjualan kepada pelanggan. Delivery order, sales invoice, beserta barang dikirim oleh staf gudang ke ekspedisi.

\subsection{Pencarian Klien}

Dalam melakukan pencarian klien, peneliti mendapatkan beberapa referensi dari berbagai pihak, hingga akhirnya peneliti bertemu dengan pemilik dari perusahaan XYZ dan perusahaan XYZ sendiri meminta peneliti untuk mengerjakan proyek ini dengan kesepakatan-kesepakatan yang telah dibuat.

\subsection{Modul yang Dikerjakan}

Modul-modul yang dibutuhkan oleh perusahaan XYZ dalam program Accurate ini meliputi beberapa hal yang tentunya merupakan hal yang fundamental bagi suatu perusahaan garmen, seperti:

Pemasukkan / revenue yang meliputi siklus penjualan dan pemasukkan lainnya. Kemudian pengeluaran / expense, yang meliputi siklus produksi, gaji karyawan, dan pembelian aset perusahaan. Ketiga ialah barang / inventory, yang meliputi penyesuaian persediaan / job costing dan pindah gudang. Keempat ialah keuangan / finance, yang meliputi pembayaran beban perusahaan dan pengisian kas kecil dan atau kas besar. Terakhir ialah laporan / reporting. Pada bagian ini laporan yang diminta untuk memenuhi kebutuhan perusahaan XYZ adalah laporan-laporan yang terkait dengan 4 (empat) poin yang sudah disebutkan di poin-poin sebelumnya, misalnya: Laporan Piutang Belum Lunas, Kartu Stok Barang.

\subsection{Instalasi Aplikasi}

Instalasi aplikasi sendiri memakan waktu sekitar 3 (tiga) hari. Meliputi transfer data dari aplikasi akuntansi yang sebelumnya dipakai oleh perusahaan XYZ, yaitu Omega, ke aplikasi yang baru yaitu Accurate, dan instalasi Accurate ke 4 (empat) komputer yang tertulis di Project Requirement System (PRS), yaitu komputer owner, komputer keuangan, komputer produksi, dan komputer penjualan. Data yang diambil untuk kebutuhan migrasi data meliputi data pelanggan, data supplier atau pemasok, data hutang yang belum terbayar, data piutang yang belum tertagih, data barang, data salesman, dan data asset. Peneliti juga meminta data rekening bank yang digunakan oleh perusahaan XYZ beserta saldo dari tiap rekening, serta saldo dari kas besar dan kas kecil perusahaan XYZ. Migrasi data tidak perlu dilakukan secara manual karena data yang diambil dari aplikasi sebelumnya yang digunakan oleh perusahaan XYZ, yaitu Omega, dapat diekspor dengan format dokumen .xls, sehingga memudahkan peneliti untuk melakukan migrasi ke Accurate.

\subsection{Hasil Implementasi}

Selama implementasi dilakukan, hasil-hasil yang bisa dibandingkan dengan software sebelumnya ialah:

1. Pengoptimalan penggunaan aplikasi Accurate untuk proses-proses yang menggunakan proses manual pada SOP sebelum menggunakan Accurate. Contoh pada proses penjualan, di mana pada software sebelumnya, surat jalan dan surat perintah pengeluaran barang jadi dari gudang atau delivery order (DO) dibuat dengan proses manual, sedangkan ketika menggunakan Accurate, surat jalan serta surat perintah pengeluaran barang jadi dari gudang tidak lagi menggunakan proses manual, melainkan menggunakan form cetak yang ada di Accurate.

2. Pengawasan data keluar masuk barang di dalam aplikasi, sehingga barang tidak bisa dikeluarkan secara sembarangan. Contoh ketika barang akan dikeluarkan untuk dikirimkan kepada pelanggan, di Accurate ketika memasuki fase delivery order, Accurate dapat mengeluarkan informasi stok barang tidak mencukupi, meskipun di data barang, stok masih ada. Hal tersebut dikarenakan karena pada saat sales order 
sudah dibuat, sedangkan delivery order belum dibuat, sistem pada Accurate sudah memotong stok barang tersebut, namun stok secara visual tidak berkurang.

3. Debit kredit yang ditampilkan di Accurate balance, sehingga memudahkan analisa neraca yang dihasilkan per bulannya.

\subsection{Pengujian Aplikasi}

Pengujian software akan dilakukan dengan menggunakan metode User Acceptance Test (UAT). UAT sendiri merupakan salah satu metode uji coba dengan cara memberikan satu kasus kepada pengguna yang nantinya akan dicatat setiap langkah per langkah yang dilakukan oleh pengguna tersebut, apakah sesuai dengan prosedur yang semestinya atau tidak.

Table 1 Skenario Pengujian Membuat Faktur Pembelian

\begin{tabular}{|c|c|}
\hline Fitur & Membuat Faktur Pembelian \\
\hline Pihak Pengguna & Owner \\
\hline $\begin{array}{l}\text { Tanggal } \\
\text { Pengujian }\end{array}$ & 20 April 2019 \\
\hline Prekondisi & $\begin{array}{l}\text { 1. Owner sudah login ke } \\
\text { dalam Accurate. } \\
\text { 2. Staf bagian produksi } \\
\text { telah membuat form } \\
\text { penerimaan barang. }\end{array}$ \\
\hline $\begin{array}{l}\text { Langkah yang } \\
\text { dijalankan } \\
\text { (penilaian) }\end{array}$ & $\begin{array}{l}\text { 1. Pada halaman utama } \\
\text { Accurate, pada bagian } \\
\text { kiri layar, klik } \\
\text { 'Pembelian', lalu pilih } \\
\text { 'Faktur Pembelian'. } \\
\text { 2. Pilih pemasok. } \\
\text { 3. Pilih form penerimaan } \\
\text { barang yang ingin } \\
\text { dibuatkan faktur. } \\
\text { 4. Masukkan nomor faktur } \\
\text { dan tanggal faktur. } \\
\text { 5. Masukkan jenis } \\
\text { pengiriman. } \\
\text { 6. Masukkan harga bahan } \\
\text { baku yang diterima. } \\
\text { 7. } \begin{array}{l}\text { Klik } \text { mendapatkan nilai faktur } \\
\text { pembelian. }\end{array} \\
\end{array}$ \\
\hline $\begin{array}{l}\text { Hasil yang } \\
\text { diharapkan }\end{array}$ & $\begin{array}{l}\text { Owner dapat membuat form } \\
\text { faktur pembelian. }\end{array}$ \\
\hline
\end{tabular}

Table 2 Skenario Pengujian Membuat Pembayaran Pembelian

\begin{tabular}{|l|l|l|}
\hline Fitur & $\begin{array}{l}\text { Membuat Pembayaran } \\
\text { Pembelian }\end{array}$ \\
\hline $\begin{array}{l}\text { Pihak } \\
\text { Pengguna }\end{array}$ & Owner \\
\hline
\end{tabular}

http://openjournal.unpam.ac.id/index.php/JTSI

\begin{tabular}{|c|c|}
\hline $\begin{array}{l}\text { Tanggal } \\
\text { Pengujian }\end{array}$ & 20 April 2019 \\
\hline Prekondisi & $\begin{array}{l}\text { 1. Owner sudah login ke } \\
\text { dalam Accurate. } \\
\text { 2. Staf bagian produksi } \\
\text { sudah membuat } \\
\text { penerimaan barang. } \\
\text { 3. Owner sudah membuat } \\
\text { faktur pembelian. }\end{array}$ \\
\hline $\begin{array}{l}\text { Langkah yang } \\
\text { dijalankan } \\
\text { (penilaian) }\end{array}$ & $\begin{array}{ll}\text { 1. } & \begin{array}{l}\text { Pada menu awal setelah } \\
\text { login, pada bagian kiri } \\
\text { layar, klik 'Pembelian', } \\
\text { lalu pilih 'Pembayaran } \\
\text { Pembelian'. } \\
\text { 2. Pilih pemasok. } \\
\text { 3. Masukkan keterangan } \\
\text { siapa yang akan } \\
\text { menerima pembayaran. } \\
\text { 4. Pilih bank yang akan } \\
\text { digunakan untuk } \\
\text { pembayaran. } \\
\text { 5. Masukkan keterangan } \\
\text { pembayaran (jika ada). } \\
\text { 6. Masukkan nomor cek } \\
\text { (jika ada). } \\
\text { 7. Pilih nota yang akan } \\
\text { dibayarkan. } \\
\text { 8. Ganti nilai pembayaran } \\
\text { (jika diperlukan). }\end{array} \\
\end{array}$ \\
\hline $\begin{array}{l}\text { Hasil yang } \\
\text { diharapkan }\end{array}$ & $\begin{array}{l}\text { Owner dapat membuat } \\
\text { pembayaran pembelian. }\end{array}$ \\
\hline
\end{tabular}

Table 3 Skenario Pengujian Membuat Faktur Penjualan

\begin{tabular}{|c|c|}
\hline Fitur & Membuat Data Faktur Penjualan \\
\hline $\begin{array}{l}\text { Pihak } \\
\text { Pengguna }\end{array}$ & Staf Bagian Penjualan \\
\hline $\begin{array}{l}\text { Tanggal } \\
\text { Pengujian }\end{array}$ & 20 April 2019 \\
\hline Prekondisi & $\begin{array}{ll}\text { 1. } & \text { Staf bagian penjualan } \\
\text { sudah login ke dalam } \\
\text { Accurate. } \\
\text { 2. }\end{array}$ \\
\hline $\begin{array}{l}\text { Langkah } \\
\text { yang } \\
\text { dijalankan } \\
\text { (penilaian) }\end{array}$ & 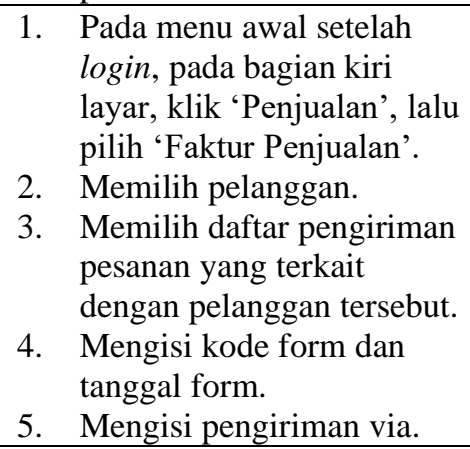 \\
\hline
\end{tabular}




\begin{tabular}{|l|l|l|}
\hline & & 6. Mengisi pajak (jika ada). \\
\hline $\begin{array}{l}\text { Hasil yang } \\
\text { diharapkan }\end{array}$ & $:$ & $\begin{array}{l}\text { Staf bagian penjualan dapat } \\
\text { membuat faktur penjualan. }\end{array}$ \\
\hline
\end{tabular}

Table 4 Skenario Pengujian Membuat Penerimaan Penjualan

\begin{tabular}{|c|c|c|}
\hline Fitur & : & $\begin{array}{l}\text { Membuat Data Penerimaan } \\
\text { Penjualan }\end{array}$ \\
\hline $\begin{array}{l}\text { Pihak } \\
\text { Pengguna }\end{array}$ & : & $\begin{array}{l}\text { Owner dan Staf Bagian } \\
\text { Keuangan }\end{array}$ \\
\hline $\begin{array}{l}\text { Tanggal } \\
\text { Pengujian }\end{array}$ & $:$ & 20 April 2019 \\
\hline Prekondisi & : & $\begin{array}{l}\text { 1. Owner dan staf bagian } \\
\text { keuangan sudah login ke } \\
\text { dalam Accurate. } \\
\text { 2. Staf bagian penjualan } \\
\text { sudah membuat pesanan } \\
\text { penjualan. } \\
\text { 3. Staf bagian penjualan } \\
\text { sudah membuat } \\
\text { pengiriman pesanan. } \\
\text { 4. } \begin{array}{l}\text { Staf bagian penjualan } \\
\text { sudah membuat faktur } \\
\text { penjualan. }\end{array} \\
\end{array}$ \\
\hline $\begin{array}{l}\text { Langkah yang } \\
\text { dijalankan } \\
\text { (penilaian) }\end{array}$ & : & $\begin{array}{l}\text { 1. Pada menu awal setelah } \\
\text { login, pada bagian kiri } \\
\text { layar, klik 'Penjualan', } \\
\text { lalu pilih 'Penerimaan } \\
\text { Pembayaran'. } \\
\text { 2. Memilih pelanggan. } \\
\text { 3. Memilih kas/bank yang } \\
\text { akan dijadikan sebagai } \\
\text { tempat uang masuk. } \\
\text { 4. Memasukkan nomor cek } \\
\text { dan tanggal cek (jika } \\
\text { ada). } \\
\text { 5. Memasukkan catatan } \\
\text { (jika ada). } \\
\text { 6. Memilih faktur yang } \\
\text { telah dibayarkan oleh } \\
\text { pelanggan. } \\
\text { Mengubah nilai faktur } \\
\text { (jika ada). } \\
\text { 8. Memasukkan nilai } \\
\text { pembayaran dengan cara } \\
\text { klik } \text { gl di sebelah kanan } \\
\text { "Cheque Amount". }\end{array}$ \\
\hline $\begin{array}{l}\text { Hasil yang } \\
\text { diharapkan }\end{array}$ & : & $\begin{array}{l}\text { Owner dan staf bagian } \\
\text { keuangan dapat membuat } \\
\text { penerimaan penjualan. }\end{array}$ \\
\hline
\end{tabular}

Table 5 Skenario Pengujian Membuka Laporan Kas Bank

\begin{tabular}{|l|c|l|}
\hline Fitur & $:$ & $\begin{array}{l}\text { Membuka Laporan Kas Bank } \\
\text { per Akun }\end{array}$ \\
\hline $\begin{array}{l}\text { Pihak } \\
\text { Pengguna }\end{array}$ & $:$ & Staf Bagian Keuangan \\
\hline
\end{tabular}

\begin{tabular}{|l|l|l|}
\hline $\begin{array}{l}\text { Tanggal } \\
\text { Pengujian }\end{array}$ & $:$ & 20 April 2019 \\
\hline Prekondisi & $:$ & $\begin{array}{l}\text { Staf bagian keuangan sudah } \\
\text { login ke dalam Accurate. }\end{array}$ \\
\hline $\begin{array}{l}\text { Langkah yang } \\
\text { dijalankan } \\
\text { (penilaian) }\end{array}$ & $:$ & $\begin{array}{l}\text { 1. Pada menu awal setelah } \\
\text { login, pada bagian atas } \\
\text { layar, klik 'Laporan', } \\
\text { lalu pilih 'Daftar } \\
\text { Laporan'. }\end{array}$ \\
$\begin{array}{l}\text { Pilih 'Laporan } \\
\text { Tersimpan', lalu pilih } \\
\text { 'Laporan Kas Bank per } \\
\text { Akun'. } \\
\text { Memilih tanggal awal } \\
\text { dan tanggal akhir. }\end{array}$ \\
\hline $\begin{array}{l}\text { Hasil yang } \\
\text { diharapkan }\end{array}$ & $:$ & $\begin{array}{l}\text { Staf bagian keuangan dapat } \\
\text { membuka laporan kas bank } \\
\text { per akun. }\end{array}$ \\
\hline
\end{tabular}

Table 6 Hasil Pengujian

\begin{tabular}{|c|c|c|}
\hline Skenario & $\begin{array}{l}\text { Hasil yang } \\
\text { Diharapkan }\end{array}$ & Hasil Pengujian \\
\hline $\begin{array}{ll}\text { 1. } & \text { Owner } \\
\text { membuat } \\
\text { faktur } \\
\text { pembelian }\end{array}$ & $\begin{array}{l}\text { Owner dapat } \\
\text { membuat } \\
\text { faktur } \\
\text { pembelian }\end{array}$ & $\begin{array}{lr}\text { Owner } & \text { dapat } \\
\text { membuat } & \text { faktur } \\
\text { pembelian } & \text { pada } \\
\text { percobaan } & \\
\text { pertama } & \\
\end{array}$ \\
\hline $\begin{array}{ll}\text { 2. } & \text { Owner } \\
\text { membuat } \\
\text { pembayaran } \\
\text { pembelian }\end{array}$ & $\begin{array}{l}\text { Owner dapat } \\
\text { membuat } \\
\text { pembayaran } \\
\text { pembelian }\end{array}$ & $\begin{array}{ll}\text { Owner dapat } \\
\text { membuat } \\
\text { pembayaran } \\
\text { pembelian pada } \\
\text { percobaan } \\
\text { pertama } & \\
\end{array}$ \\
\hline $\begin{array}{ll}\text { 3. } & \text { Staf bagian } \\
\text { penjualan } \\
\text { membuat } \\
\text { faktur } \\
\text { penjualan }\end{array}$ & $\begin{array}{l}\text { Staf bagian } \\
\text { penjualan } \\
\text { dapat } \\
\text { membuat } \\
\text { faktur } \\
\text { penjualan }\end{array}$ & $\begin{array}{lr}\text { Staf } & \text { bagian } \\
\text { penjualan } & \text { dapat } \\
\text { membuat } & \text { faktur } \\
\text { penjualan } & \text { pada } \\
\text { percobaan } & \\
\text { pertama } & \\
\end{array}$ \\
\hline $\begin{array}{l}\text { 4. Owner dan staf } \\
\text { bagian } \\
\text { keuangan } \\
\text { membuat } \\
\text { penerimaan } \\
\text { penjualan }\end{array}$ & $\begin{array}{l}\text { Owner dan } \\
\text { staf bagian } \\
\text { keuangan } \\
\text { dapat } \\
\text { membuat } \\
\text { penerimaan } \\
\text { penjualan }\end{array}$ & $\begin{array}{l}\text { Owner dan staf } \\
\text { bagian keuangan } \\
\text { dapat membuat } \\
\text { penerimaan } \\
\text { penjualan pada } \\
\text { percobaan } \\
\text { pertama }\end{array}$ \\
\hline $\begin{array}{ll}\text { 5. } & \text { Staf bagian } \\
\text { keuangan } \\
\text { membuka } \\
\text { laporan kas } \\
\text { bank per akun }\end{array}$ & $\begin{array}{l}\text { Staf bagian } \\
\text { keuangan } \\
\text { dapat } \\
\text { membuka } \\
\text { laporan kas } \\
\text { bank per akun }\end{array}$ & $\begin{array}{l}\text { Staf bagian } \\
\text { keuangan dapat } \\
\text { membuka laporan } \\
\text { kas bank per akun } \\
\text { pada percobaan } \\
\text { pertama }\end{array}$ \\
\hline
\end{tabular}

\section{Kesimpulan}

Berdasarkan apa yang sudah dilakukan selama penelitian ini, yaitu implementasi Accurate pada perusahaan XYZ, kesimpulan yang didapat adalah sebagai berikut:

1. Berkat adanya perubahan-perubahan pada Standar Operasional Prosedur (SOP) yang dibuat untuk menyesuaikan kebutuhan 
perusahaan XYZ dalam menggunakan Accurate, membuat proses bisnis menjadi lebih efisien serta meminimalisir terjadinya fraud atau kecurangan yang terjadi selama proses bisnis berlangsung.

2. Dengan adanya Accurate 4 Enterprise Edition ini, perusahaan jadi lebih tahu berapa selisih antara kredit dan debit dalam laporan neraca perusahaan, yang nantinya digunakan untuk meneliti laba rugi perusahaan pada periode tertentu.

3. Accurate 4 Enterprise Edition yang diimplementasikan kepada perusahaan XYZ dapat memenuhi kebutuhan perusahaan dalam pencatatan proses pembelian dan penjualan.

\section{Referensi}

Anggraeni, E.Y., Irviani, R. (2017). Pengantar Sistemm Informasi. Yogyakarta: Penerbit Andi.

Dachi, R.A. (2017). Proses dan Analisis Kebijakan Kesehatan (Suatu Pendekatan Konseptual). Yogyakarta: Deepublish.

Edi, F.R.S. (2016). Teori Wawancara Psikodignostik. Yogyakarta: LeutikaPrio.
Hareka, W.A., Tanamal, R. (2018). Rancang Bangun Aplikasi Sistem Pakar Berbasis Android Untuk Memprediksi Kerusakan Pada Mesin Sepeda Motor Yamaha R25. JURTI. 2(2): 202-203.

Mahaymyo, A. (2014). Sistem Informasi Akuntansi Suatu Pengantar. Yogyakarta: Deepublish

Marina, A. d. (2017). Sistem Informasi Akuntansi : Teori dan Praktikal. Surabaya: UMSurabaya Publishing.

Ni'matuzaroh, Prasetyaningrum, S. (2018). Observasi: Teori dan Aplikasi dalam Psikologi. Malang: Universitas Muhammadiyah Malang.

Raco. J.R. (2010). Metode Penelitian Kualitatif. Jakarta: Grasindo.

Soemohadiwidjojo, A.T. (2014). Mudah Menyusun SOP Standard Operational Procedure. Jakarta: Penebar Plus.

Wijaya, Z. S. (2015). Penerapan Sistem Informasi Berbasis Komputer Pada Aplikasi Monitoring Keuangan dan Aset (Terkait Penatausahaan Piutang Tuntutan Ganti Kerugian Negara). Jurnal Ekonomi Akuntansi dan Manajemen (JEAM) Vol 14, No 2 : Universitas Jember. 